\title{
RV/TLC\% ratio: alternative criteria of normality
}

\section{To the Editor:}

Although the European Respiratory Society (ERS) proposes using percentiles or standardized residuals for reporting results of lung volume measurements [1], this approach has not been widely accepted, and percentages are still being used, mainly because calculations and interpretation are easier to perform.

Our group has reported that both for spirometry [2] and total lung capacity (TLC) measurement [3] it is possible to find values of percentage of predicted that adequately meet the ERS standard, so that these values can be used in daily practice.

The aim of the present study was to find values of residual volume (RV)/TLC\% that could be used instead of percentiles and standardized residuals in clinical practice. We have analysed lung volume measurements performed in 212 consecutive patients (151 males and 61 females) aged 53 \pm 12 yrs (18-70 yrs) in 1993. For each patient, spirometry, body plethysmography and single-breath helium dilution were performed in turn in a Masterlab system (Jaeger) under basal conditions. We have considered the standard upper limit of normality (ULN) of RV/TLC\% to be the 95th percentile, as stated by the ERS, and we have calculated it as mean+ 1.6449.standard error, using the ERS prediction equations [1]. Alternative methods to be tested are two previously published ones cut-off point between normality and abnormality at an actual value of RV/TLC $\%$ of $40 \%$, or $120 \%$ of predicted [4], and the ones we propose, based on cut-off points found by trial. Agreement analysis has been made according to the guidelines of BRENNAN and SILMAN [5], both for plethysmographic measurements and for helium-dilution. Our main results are presented in table 1 .

Table 1. - Cut-off points between normal and abnormal RV/TLC\%. Agreement and bias

\begin{tabular}{lcccll}
\hline \multicolumn{2}{c}{$\begin{array}{c}\text { Normal } \\
\%\end{array}$} & $\begin{array}{c}\text { Abnormal } \\
\%\end{array}$ & $\begin{array}{c}\text { kappa } \\
\%\end{array}$ & Bias & p-value \\
\hline \multicolumn{2}{l}{ Plethysmography } \\
Actual & $\leq 40$ & $>40$ & 79.5 & Yes & 0.0006 \\
$\%$ pred & $\leq 120$ & $>120$ & 49.7 & Yes & 0 \\
Actual & $\leq 48$ & $>48$ & 85.7 & No & 0.547 \\
$\%$ pred $\leq 126$ & $>126$ & 94.8 & No & 0.617 \\
Helium dilution & & & & \\
Actual & $\leq 40$ & $>40$ & 90.6 & No & 0.067 \\
$\%$ pred $\leq 120$ & $>120$ & 47.5 & Yes & 0 \\
Actual & $\leq 47$ & $>47$ & 89.9 & No & 0.617 \\
$\%$ pred & $\leq 128$ & $>128$ & 97.4 & No & 1 \\
\hline
\end{tabular}

RV: residual volume; TLC: total lung capacity; $\%$ pred: percentage of predicted value.
Plethysmography: mean value of RV/TLC $\%$ is $39.7 \pm$ $11.6 \%$ (mean $\pm \mathrm{SD}$ ), which is $112 \pm 28 \%$ of predicted (standardized residual: 0.791 \pm 1.8008$)$. Kappa index, when ULN is set at $120 \%$ of predicted, is $79.5 \%$ (good agreement), and bias is present. Setting the ULN at $40 \%$ yields a moderate agreement (kappa is $49.7 \%$ ), with significant bias. The proposed methods for plethysmographic measurements are $126 \%$ for percentage of predicted ( $\kappa=94.8 \%$, no bias) and $48 \%$ for the actual value $(\kappa=85.7 \%$, no bias). Since it has been proposed not to use fixed values for indices that, like forced expiratory volume in one second (FEV1)/VC\%, change with age [6], I prefer using percentage of predicted (which varies with ageing), which in addition has the highest value of kappa.

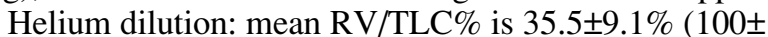
$20 \%$ of predicted), or, in standardized residuals, $0.027 \pm$ 1.310. Kappa, when ULN is set at $120 \%$ of predicted, $90.6 \%$ (very good agreement) and no bias is present; for an actual value of $40 \%$, kappa is $47.5 \%$ (moderate agreement), and bias is present. Values of kappa for the proposed methods (ULN at $128 \%$ of predicted, and $47 \%$ as the actual value) are, respectively, $97.4 \%$ and $89.9 \%$ (very good agreement in both cases), with no bias. In this case I also prefer using percentage of predicted, for reasons already explained.

It has been shown that percentage-based methods are available that can be used in clinical practice instead of percentile-based ones: air-trapping if RV/TLC\% is higher than $126 \%$ of predicted by the plethysmographic method or $128 \%$ of predicted by the helium dilution method, and no air-trapping if RV/TLC\% is equal to or under those values; however, standardized residuals should be used for investigative purposes. I have not found any satisfactory explanation for the small difference between the cut-off points set for both methods of lung volume measurement, but I think this difference has no practical meaning.

\section{References}

1. Stocks J, Quanjer PhH. Reference values for residual volume, functional residual capacity and total lung capacity. ATS Workshop on lung volume measurement. Official statement of the European Respiratory Society. Eur Respir J 1995; 8: 492-506.

2. Díez Herranz A, Para Cabello J, Fernández Rodríguez ML. Validación de diversos criterios de interpretación de la espirometría forzada. Estudio preliminar. Arch Bronconeumol 1994; 30: 418-419.

3. Díez Herranz A, Teruel González FE, Aller Alvarez JL. Concordancia entre diferentes criterios de normalidad de los volúmenes pulmonares. Arch Bronconeumol 1995; 31: 43. 
4. Roca Torrent J, Ballester Rodes E, Ussetti Gil P. Bases anatómicas y exploración de la función pulmonar. In: Agusti Vidal A, ed. Neumología básica. Madrid, IDEPSA, 1986; pp. 3-23.

5. Brennan P, Silman A. Statistical methods for assessing observer variability in clinical measures. Br Med J 1992; 304: 1491-1494.
6. American Thoracic Society. Lung function testing: selection of reference values and interpretative strategies. $\mathrm{Am}$ Rev Respir Dis 1991; 144: 1202-1218.

\section{A. Diez Herranz}

Servicio de Neumologica, Hospital

Militar, Valladolid, Spain.

\section{REPLY}

\section{From the authors:}

A. Diez Herranz addresses a problem which many people are grappling with. Why did the European Coal and Steel Community (ECSC), the European Respiratory Society (ERS) and the American Thoracic Society (ATS) [1-4] recommend standardized residuals rather than the familiar percentage predicted recommended for use in evaluating ventilatory function? The reason is as follows. In large cross-sectional studies, much of the difference in ventilatory function between individuals could be statistically explained by differences in stature, age and gender; the remaining or residual variance (the square root of which gives the residual standard deviation: RSD) was independent of the level of lung function. Let us apply this to two males of $1.75 \mathrm{~m}$ standing height, aged 25 and $65 \mathrm{yrs:}$ the predicted forced expiratory volume in one second (FEV1) comes to 4.31 and $3.15 \mathrm{~L}$, respectively, and the associated RSD is $0.51 \mathrm{~L}$ [3]. We actually record a FEV1 of 3.47 and $2.31 \mathrm{~L}$, respectively: in both cases, this is $0.84 \mathrm{~L}$ or $0.84 / 0.51$ $=1.64$ standardized residuals below the predicted mean, so that the two individuals are at about the lower 5th percentile for a reference population, and quite comparable. The observed value as a percentage of predicted mean comes to 81 and $73 \%$, respectively. The percentage predicted introduces an appreciable difference, which cannot be justified on the basis of the original data on which the predictions were based, since the residual scatter was unrelated to the average level of the index. Hence, if ventilatory function declines or increases with age and the scatter around predicted is by and large constant, then taking the ratio of observed and predicted introduces an age-related bias, an undesirable feature. Obviously, such spurious results may also arise from differences in stature.

A. Diez Herranz has taken a sample from his clinical population and adopted an arbitrarily defined percentage predicted as a cut-off point; he also applied the ECSCERS-ATS recommendation. The proportion agreement of "positive" and "negative" test results varied from good to moderate. Surely, the agreement reflected by kappa depends on the sample of subjects. To take an extreme example, if the residual volume (RV) in all subjects would be very much elevated there would be perfect agreement between both methods of evaluating lung function, and in practice it would be irrelevant which method one applied. In other circumstances, with a varying mix of very pathological and normal observations, the agreement would vary. Cut-off criteria for percentage predicted, which might prove satisfactory in, say, a population of predominantly elderly persons, would have to be adjusted if they were to be applied to a younger and possibly taller population. In contrast, the standardized residual method applies without adjustments in both circumstances. A very convenient feature is that when residuals have a normal distribution and are independent of the mean, irrespective of the index of interest, if the original sample was large, upper and lower percentiles can be approximated by only one figure. Thus, the 5 th percentile is 1.64.RSD below the predicted mean, the 97.5 th percentile is 1.96 . RSD above mean (in practice one can assume that $95 \%$ of the population is between \pm 2 RSD of the mean). Irrespective of the above objections, percentage predicted limits will vary from index to index. The above example shows that the computation of the standardized residual cannot possibly be regarded as complex.

In medicine, it is more or less standard practice, when confronted with two related measurements, to perform data reduction by expressing one as a percentage of the other. Ratios are in place if variables are proportionally related, which is usually not the case (consult references cited in [1-4]). As a rule, the percentage predicted approach in adults cannot, therefore, be scientifically justified.

\section{References}

1. Quanjer $\mathrm{PhH}$ (ed). Standardized lung function testing. Report Working Party "Standardization of Lung Function Tests", European Coal and Steel Community. Bull Eur Physiopathol Respir 1983; 19 (Suppl. 5): 1-95.

2. ATS Statement. Lung function testing: selection of reference values and interpretative strategies. Am Rev Respir Dis 1991; 144: 1202-1218.

3. Quanjer PhH, Tammeling GJ, Cotes JE, Pedersen OF, Peslin R, Yernault J-C. Lung volumes and forced ventilatory flows. Report Working Party "Standardization of Lung Function Tests", European Coal and Steel Community. Official statement of the European Respiratory Society. Eur Respir J 1993; 6 (Suppl. 16): 5-40.

4. Stocks J, Quanjer PhH. Reference values for residual volume, functional residual capacity and total lung capacity. ATS Workshop on lung volume measurements. Official statement of the European Respiratory Society. Eur Respir J 1995; 8: 492-506.

Ph.H. Quanjer

Dept. Physiology, Leiden University

Leiden, The Netherlands. 